\title{
Applying Salutogenesis in Mental Healthcare Settings
}

\author{
Eva Langeland and Hege Forbech Vinje
}

\section{Introduction}

Aaron Antonovsky's crucial theoretical proposition was that how human beings perceive reality in terms of comprehensibility, manageability, and meaningfulness, which together form sense of coherence, contributes to coping, health, and well-being. Research shows that sense of coherence is especially related to mental health (Eriksson \& Lindstrøm, 2006). Mental health in a salutogenic perspective refers to a person's position, at any point in the life cycle, on "... a continuum that ranges from excruciating emotional pain and total psychological malfunctioning at one extreme to a full, vibrant sense of psychological well-being at the other" (Antonovsky, 1985, p. 274).

Although Antonovsky was a researcher and not a clinician, he claimed that salutogenesis "has something to say to all those who, professionally and personally, are committed to understanding and enhancing the adaptive capacities of human beings" (Antonovsky, 1979, preface p. viii). His challenge to different health professionals revealed that he wrote not only for his major reference group; his colleagues in medical sociology. He mentions sociologists, psychologists, psychiatric nurses, physicians, healthcare organizers, epidemiologists, architects, and community organizers as his intended audience (Antonovsky, 1979, preface p. viii).

Since Antonovsky was primarily a researcher, he did not work so much with the operationalization of salutogenesis in

This chapter is a revision and update of work published in Mittelmark, M.B., Sagy, S., Eriksson, M., Bauer, G., Pelikan, J.M., Lindström, B., \& Espnes, G.A. (eds). (2017). The Handbook of Salutogenesis. Springer, Cham. DOI: https://doi.org/10.1007/978-3-319-04600-6.

E. Langeland $(\bowtie)$

Department of Health and Caring Sciences, Faculty of Health and

Social Sciences, Western Norway University of Applied Sciences,

Bergen, Norway

e-mail: Eva.Langeland@hvl.no

H. F. Vinje

THE FORBECH VINJE ACADEMY (www.forbechvinje.no),

Sandefjord, Norway clinical settings, even if he did present some cases that revealed the difference between a salutogenic and pathogenic approach (Antonovsky, 1987, p. 9-10). The relevance of applying salutogenesis in clinical settings is obvious, and Antonovsky suggested that every health professional should include aims in their clinical practice that promote peoples' sense of coherence.

Health promotion in mental healthcare may work at three levels: strengthening individuals, strengthening communities, and reducing structural barriers to mental health (WHO, 2005). This involves a reorientation from the medical model to a more inclusive and holistic one. It could be said that the professional mental health promoter has a role as an expert in mental health in general. At the collective level, the professional mental health worker aims to develop structures that enable people with mental health problems to empower themselves through, for example, gaining access to and making use of resources like material goods and social services. At the individual level, the professional aspires to be an expert and to create a conversational and interactional climate that will promote desirable change for and in the recipient of the mental healthcare service. A fundamental attitude is that people are experts on themselves and their unique situations and experiences, including their pain, suffering, and concerns. Subsequently, the professional mental health worker functions more as a dialogue partner, balancing between listening empathetically to participants' difficulties and taking into account their strengths and resources (Duncan et al., 2010).

\section{Mental Health and Mental Health Challenges}

Antonovsky (1985) claims that our role as scientists or therapists concerned with mental health is to gain an increased understanding of the challenges posed in the life cycle of the human being and the factors which shape the selection of responses. Antonovsky describes the movement on the continuum toward better mental health as shifting: 
...-from the use of unconscious psychological defence mechanisms toward the use of conscious coping mechanisms;- - from the rigidity of defensive structures to the capacity for constant and creative inner readjustment and growth;- - from a waste of emotional energy toward its productive use; from emotional suffering toward joy;- - from narcissism toward giving of oneself;from exploitation of others to reciprocal interaction (Antonovsky, 1985 , p. 274).

In the present chapter, mental illness, mental suffering, mental disorders, mental problems, and psychosocial problems are conceptualized as mental health challenges, in concert with the salutogenic model of health. Antonovsky (1985, p. 274) emphasized that he used the word challenges rather than stressors, conflicts, or problems; the latter implies an unwelcome burden, while "challenges" are far more open to initiating an interaction which may end catastrophically ... or joyfully. Further, "challenges" are less disease-focused and encourages one to keep in mind that, despite suffering from mental illness, there always is some level of health and resources present that can be recognized, utilized, and nurtured. It thus corresponds more to the positive mental health concept and that tension, the state of psychophysiological responses of the organism to challenge, is not necessarily pathogenic (Antonovsky, 1985, 1987; Berger, 2003; Langeland, 2007).

\section{Applying Salutogenesis in Mental Healthcare Settings}

While salutogenesis is a design for health, pathogenesis is a design for disease. However, the traditional perspective or design in healthcare has been and still is pathogenesis. Becker and Rhynders (2013) illustrate this by referring to a presentation by Deming (2000) that uses a marine metaphor and asks, "What determines how fast a ship moves?" The answers include currents, sails, the crew, and the weather. All these factors may, of course, have an impact on the speed. However, only the ship designer determines the capacity of how fast a ship might move, regardless of the conditions. For health, our design has been pathogenesis, a design for disease. Salutogenesis provides a new design that enables faster progress toward better health by helping health professionals' practices to be about health (Becker \& Rhynders, 2013).

Jormfeldt (2011) illuminates this through an example of how a focus on diagnosis (pathogenesis) versus a focus on the person (salutogenesis) might be displayed in clinical mental health work. When looking at schizophrenia from a biomedical point of view, medication and the person's compliance are emphasized. It is easy to understand that the individual's motivation to sustain hope is reduced in such a context. In a salutogenic perspective, the attention is to the individual's own experience, including his- tory, wishes, dreams, and experiences here and now. If medication is applied, it is for supporting the person to achieve one's own goals.

\section{Salutogenic Talk Therapy}

The first intervention program based on the entire salutogenic model of health and aimed to strengthen sense of coherence as a main outcome was developed by Langeland et al. in 2007 (discussed in Yamazaki et al., 2011) and further developed in Langeland and Vinje (2013). This intervention was implemented in talk-therapy groups for people with mental health challenges. It has been evaluated in a randomized controlled trial, showing positive effects on the sense of coherence. In addition, an evaluation performed by the study's participants revealed that between $85 \%$ and $95 \%$ experienced their participation as contributing greatly to improving their mental health in everyday life (Langeland et al., 2006). Further, to increase knowledge about salutogenic processes, in-depth interviews have been performed with people who have participated in a salutogenic talktherapy group. The findings indicate that participants strengthen their consciousness and use of general resistance resources (GRRs) and specific resistance resources (SRRs), thus promoting their sense of coherence (SOC), salutogenic capacity, and mental health (Langeland et al., 2016).

The main aim of this salutogenic approach is to increase participants' awareness of and confidence in their potential, their internal, and external resources, and their ability to use these to increase their sense of coherence, coping, and level of mental health and well-being. In applying a salutogenic approach, one is encouraged to search for and identify individual and collective generalized resistance resources that may promote the effective management of tension in demanding situations. Higher levels of generalized resistance resources are associated with a stronger sense of coherence. Due to the changing nature of human/environment interactions, it is not possible to make a list and identify all possible generalized resistance resources. Therefore, Antonovsky (1979, p. 99) formulated the following definition: "every characterization of a person, group or environment that promotes effective management of tension." The relationship between resistance resources and the sense of coherence is reciprocal (Antonovsky, 1979; Landsverk \& Kane, 1998). For example, social support leads to a stronger sense of coherence, which enables a person to mobilize and make use of social support. When people experience concordance between their use of generalized resistance resources and their expectations, wishes, and demands, life's challenges are experienced as appropriate, and thus tension is transformed into coping. The experience of appropriate chal- 
lenges (balance between overload and overload) in daily life strengthens sense of coherence (Langeland et al., 2007).

In this regard, it is crucial to understand tension as potentially health-promoting and to distinguish between tension and stress (Antonovsky, 1987, p. 8). Tension is understood as a normal and necessary feeling for coping. The concept of flow (Csikszentmihayi, 1997) may shed some light on the significance of appropriate challenges and the strengthening of the sense of coherence:

Flow tends to occur when a person's skills are fully involved in overcoming a challenge that is just about manageable. Optimal experiences usually involve a fine balance between one's ability to act and the available opportunities for action (Csikszentmihayi, 1997, p. 30)

Accordingly, the key is to acquire good coping experiences by perceiving appropriate challenges. Lutz (2009) suggests that flow may be sense of coherence experienced in the here and now, while sense of coherence is also a product of flow over time. Figure 39.1 illustrates the positive interplay between sense of coherence and the use of resistance resources. The person is an open system that contains social, psychological, and genetic subsystems, but it is the integration of the whole that is emphasized in the concept of sense of coherence (Sullivan, 1989).

In the talk-therapy setting, the aim is to promote a person's sense of coherence; it is thus important to support the individual's understanding of her own situation and diagnosis. A high level of comprehensibility promotes a good capacity to judge reality (Antonovsky, 1979, p. 127). Langeland et al. (2007) suggest defining diagnosis as but one dimension of the person; a fundamental aim is that the person with a diagnosis experience understands herself primarily as a person and not as a diagnosis. This is crucial in order to prevent the stigmatization that can follow if everything that a person says or does is interpreted in relation to the

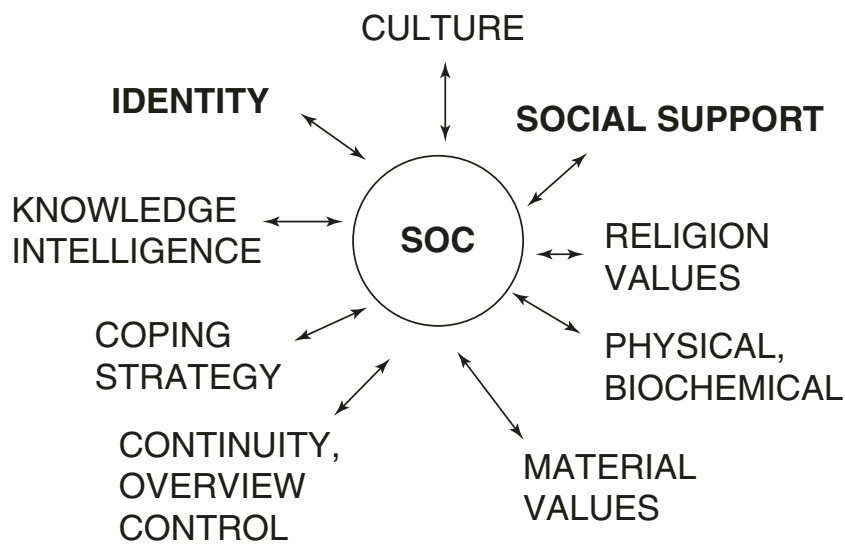

Fig. 39.1 The interplay between resistance resources and the sense of coherence (SOC) diagnosis. When this happens, the person loses the right to be a human being with normal feelings and thoughts. Human beings construct meaning and coherence by telling their own stories, and it is important to emphasize the coping in their stories in order to assist the person in developing a constructive narrative identity.

Another critical feature of the talk-therapy setting is that the person identifies internal and external resources that make her manage the situation better. The emphasis is on what functions to promote a person's health. This includes increased consciousness of resources and support factors that function well in a person's life. Internal and external resources might include culture, outdoor life, music, humor, relationships, adaptive strategies, coping strategies, good inner dialogue, reflection, and knowledge acquisition.

Further, the talk-therapy setting is partly dedicated to supporting a person's exploration of what gives life meaning. Mental health is much more than and not necessarily the lowest level of suffering. For example, an individual who wants to commit suicide needs - in addition to action that prevents her from succeeding - facilitation to find out what makes life worth living. According to Antonovsky, one has to invest in inner feelings, immediate personal relationships, major activity, and existential issues (Antonovsky, 1987, p. 139), if one does not want to lose resources and meaning over time. This means, as Lindstrøm (2001) explains, that it is important to be able to form a view of life (ideological, religious, or political), to know people one perceives to be supportive (the function of social support), to have mental stability, and to be involved in rewarding everyday activities, such as work, sports, education, etc. In salutogenic talktherapy groups, an important part is homework based on these crucial spheres. Langeland et al. (2007) gives examples of such homework. The homework might function as an inner voice, much like a continuation of the group, which helps to increase the impact of the group.

Finally, yet importantly, the main focus in salutogenic talk therapy is to draw attention to a person's adaptive capacity and the ability to activate adaptation (individually tailored) to various challenging situations through creative processes, thus promoting sense of coherence in everyday life (Table 39.1).

\section{Other Perspectives on Salutogenesis and Therapy}

Consistent with the experience of talk therapy just described, Griffiths (2009) concluded in a literature review that it might be advantageous to include therapy goals based on the sense of coherence in mental health rehabilitation with people hav- 
Table 39.1 A mental health promotion process based on the salutogenic model of health

\begin{tabular}{|c|c|c|}
\hline Salutogenesis & Salutogenic principles & Desired outcomes \\
\hline \multirow[t]{3}{*}{$\begin{array}{l}\text { 1. Health as } \\
\text { continuum }\end{array}$} & $\begin{array}{l}\text { Movement toward } \\
\text { health }\end{array}$ & $\begin{array}{l}\text { Increasing tolerance for } \\
\text { various feelings }\end{array}$ \\
\hline & $\begin{array}{l}\text { Universalizing } \\
\text { mental health } \\
\text { challenges }\end{array}$ & \multirow[t]{2}{*}{$\begin{array}{l}\text { Improving active } \\
\text { adaptation }\end{array}$} \\
\hline & $\begin{array}{l}\text { Introducing the } \\
\text { metaphor of the } \\
\text { stream of life }\end{array}$ & \\
\hline \multirow[t]{3}{*}{$\begin{array}{l}\text { 2. The story of } \\
\text { the participant }\end{array}$} & $\begin{array}{l}\text { Diagnosis as a } \\
\text { narrow description }\end{array}$ & $\begin{array}{l}\text { Experiencing oneself as a } \\
\text { person }\end{array}$ \\
\hline & \multirow{2}{*}{$\begin{array}{l}\text { Listening to the } \\
\text { participant's } \\
\text { narrative identity: } \\
\text { Shedding light on } \\
\text { individual coping } \\
\text { ability }\end{array}$} & $\begin{array}{l}\text { Structuring life experiences } \\
\text { that reinforce sense of } \\
\text { coherence }\end{array}$ \\
\hline & & $\begin{array}{l}\text { Increasing perception of } \\
\text { coping in the narrative } \\
\text { identity }\end{array}$ \\
\hline \multirow{3}{*}{$\begin{array}{l}\text { 3. Health- } \\
\text { promoting } \\
\text { (salutary) } \\
\text { factors }\end{array}$} & $\begin{array}{l}\text { Extending coping } \\
\text { resources }\end{array}$ & Improving self-identity \\
\hline & $\begin{array}{l}\text { Paying attention to } \\
\text { what is currently } \\
\text { functioning well } \\
\text { and asking } \\
\text { questions to } \\
\text { increase the } \\
\text { awareness of } \\
\text { resources }\end{array}$ & \multirow[t]{2}{*}{$\begin{array}{l}\text { Increasing perception of } \\
\text { the quality of social } \\
\text { support such as } \\
\text { attachment, social } \\
\text { integration, opportunity for } \\
\text { nurturing, reassurance of } \\
\text { worth, reliable alliance, } \\
\text { and guidance }\end{array}$} \\
\hline & $\begin{array}{l}\text { Promoting } \\
\text { resistance resources, } \\
\text { particularly social } \\
\text { support and } \\
\text { self-identity }\end{array}$ & \\
\hline \multirow{2}{*}{$\begin{array}{l}\text { 4. Stress, } \\
\text { tension, and } \\
\text { strain as } \\
\text { potentially } \\
\text { health } \\
\text { promoting }\end{array}$} & $\begin{array}{l}\text { Discussing } \\
\text { appropriate } \\
\text { challenges }\end{array}$ & $\begin{array}{l}\text { Increasing acceptance of } \\
\text { one's own potential and } \\
\text { coping ability }\end{array}$ \\
\hline & $\begin{array}{l}\text { Universalizing the } \\
\text { feelings of tension }\end{array}$ & $\begin{array}{l}\text { Experiencing one's } \\
\text { resources }\end{array}$ \\
\hline \multirow[t]{3}{*}{$\begin{array}{l}5 . \text { Active } \\
\text { adaptation }\end{array}$} & $\begin{array}{l}\text { Promoting a climate } \\
\text { of unconditional } \\
\text { positive regard, } \\
\text { empathy, and } \\
\text { genuineness }\end{array}$ & $\begin{array}{l}\text { Experiencing motivation } \\
\text { for change }\end{array}$ \\
\hline & $\begin{array}{l}\text { Developing } \\
\text { participants' unique } \\
\text { capacities }\end{array}$ & $\begin{array}{l}\text { Thinking more salutogenic } \\
\text { and developing positive } \\
\text { patterns for health } \\
\text { promotion }\end{array}$ \\
\hline & $\begin{array}{l}\text { Developing crucial } \\
\text { spheres in human } \\
\text { existence }\end{array}$ & $\begin{array}{l}\text { Increasing perceptions of } \\
\text { comprehensibility, } \\
\text { manageability, and } \\
\text { meaning; improving SOC }\end{array}$ \\
\hline
\end{tabular}

Based on Langeland et al., 2007. Issues in Mental Health Nursing, 28, 275-295. Taylor \& Francis Ltd. www.tandfonline.com. All rights reserved

ing various mental health challenges such as schizophrenia, psychosis, addiction, and depression. Menzies (2000) elaborated on how a psychiatric nurse might apply a salutogenic approach to a person diagnosed with schizophrenia: talking about managing and coping with symptoms and problems, fostering hope by discussing possibilities, and supporting increased consciousness of abilities and skills, thus contributing to self-esteem, identity, and sense of coherence.

Joachim et al. (2003) discussed the treatment of obsessivecompulsive disorder based on strengthening the sense of coherence: based on a literature review they illuminate how emphasizing comprehensibility, manageability, and meaning help improve self-efficacy, coping, and control, and reduce vulnerability and repeated compulsions. Since comprehensibility includes how one perceives stimuli from internal and external surroundings, the first aim in this therapy is to increase comprehensibility. Manageability might be increased by identifying specific strategies to tackle challenges such as the side effects of medicines, compulsive symptoms, and changes in thoughts and actions, thus creating coping experiences. The alliance between therapist and client is emphasized, and an atmosphere of trust and acceptance is basic. Meaning is explored as the client is helped to cope better with anxiety and becomes more able to explore spheres in life that he/she earlier has avoided. Hence, purpose and meaning in life are enhanced. Vital in this program is not to find the reasons for the suffering, but rather to develop strategies to change thoughts and actions. To structure treatment of obsessive-compulsive disorder using sense of coherence as a framework facilitates exploring emotional reactions and developing constructive patterns by encouraging acceptance, stimulating new strategies, and managing negative feelings. Accordingly, the person is strengthened in her efforts to take more responsibility for her health and discover resources and relations that promote growth and wellbeing in his/her everyday life.

Landsverk and Kane (1998) show how salutogenesis and the sense of coherence concept might be used as a theoretical basis for "psychoeducation" that strengthens stress-reducing skills, promotes assertiveness, and recognition and mastery of symptoms. Also, central to this strategy is raising awareness of social support and a supportive environment, and enabling the person in identifying, assessing, and using the resources available. In addition, they emphasize that to share coping stories creates optimism and confidence in one's strengths.

\section{Social Support}

Since social support and self-identity (in bold in Fig. 39.1) are crucial resistance resources (Antonovsky, 1987), these are further elaborated here. Different types of social support provide different resistance resources (Cutrona \& Russell, 1987). Because life situations vary in adaptation 
demands, a given type of social support will be effective only when the resistance resource it provides is matched to the demands of the situation (ibid). Weiss (1974) has identified six social functions or provisions that might be obtained from others: attachment, social integration, opportunity for nurturance, reassurance of worth, reliable alliance, and guidance. This finer-grained approach to the conceptualization of social support could have important implications for mental health interventions. In talk therapy, an attempt could be made to emphasize these six relational provisions explicitly. For example, talk-therapy group facilitators might try to increase group members' awareness of opportunities for nurturing. Research reveals that the ability to give nurturance is especially important in raising consciousness among people with mental health problems because they often are recipients of care; accordingly, their coping may be strengthened (Langeland \& Wahl, 2009). Their strengthened social competence may subsequently be applied in other settings.

\section{Salutogenic Self-Identity}

Mental health professionals often wish to be able to facilitate the development of positive self-identity in their clients. Positive self-identity is a vital resistance resource (Antonovsky, 1987) and a crucial aim in talk-therapy groups based on salutogenesis. For example, one might encourage a client to undertake constructive actions or activities whose rewarding outcomes improve self-identity. Increasing participants' consciousness of their own possible choices in different challenging situations is, therefore, key in salutogenic conversations. As an example of this, Magrin et al. (2006) have developed a psychological intervention named The power of stress: a salutogenic model of intervention. The aim is to develop a salutogenic coping style by concentrating on finding meaning and thus promoting identity. A crucial acknowledgment is that well-being is a continuous process that individuals themselves are influencing. An important element in the intervention of Magrin et al. (2006) is the salutogenic understanding of tension. Tension is a normal feeling when facing challenges, and it is essential to accept this; otherwise, a person does not experience coping and thus develops a stronger identity. Magrin et al. (2006) suggest that tension might be seen as the "salt of life." The intervention consists of two phases, and the first is to discover meaning through working with identity. The phase focuses on individuals exploring who they are by working with desires for life and how they understand tension and stress. The aim is to perceive tension as a salutogenic factor in one's internal and external environment. Phase II focuses on developing the courage to live as one wishes. In this phase, the individual moves from getting in contact with one's own potential to acknowledging own ability to take action and realize own competence, and through that experience the positive potential of tension and gradually developing a salutogenic coping style.

Højdahl et al. (2013) have developed an intervention based on salutogenesis for convicted women called the VINN-program ("vinn" is the Norwegian word for "win" or "overcome"). The intervention concentrates on teaching participants how to identify and mobilize coping resources in order to meet and manage demands, risk-situations, and stressors, thus promoting identity and the sense of coherence. Homework, relaxing exercises, and every group session is structured around the topics identity, health, and relations. Moreover, the participants are encouraged to search for and identify meaningful activities to engage in. Each participant's personal motivation and commitment to change behavior is purposefully stimulated, within a group atmosphere of acceptance and compassion (ibid).

Social support and identity are very closely related to an individual's identity as developed through social relationships. While Antonovsky uses the metaphor about health in the river of life and active adaptation by swimming (Antonovsky, 1987), the Norwegian professor Per Fugelli uses the metaphor of "dancing with your flocks," and claims that your identity is formed by how one dances with one's flocks such as one's family, colleagues, and friends (Fugelli, 2012). This is why the qualities of our flocks are so important. A good life is not promoted in social isolation; it is created in flocks with qualities that foster dignity, belonging, and safety (Fugelli, 2012). Related to this idea, we have followed the progress of salutogenic talk-therapy groups, and we have clear evidence for a process stimulating active adaptation and coping with tension, based on the interplay of social support and identity (Fig. 39.2). It is particularly

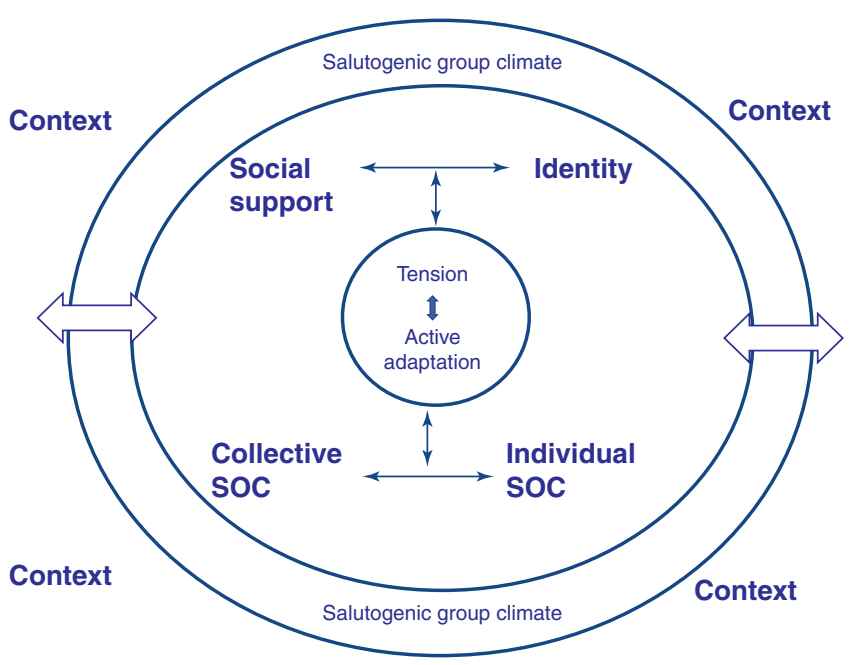

Fig. 39.2 Salutogenic talk-therapy group climate 
apparent that it is the trustful climate of a group that encourages the opening up of one to oneself and to other group members (Langeland et al., 2016; Langeland \& Vinje, 2013). The willingness to reveal one's vulnerability in the caring, accepting, and trustful group atmosphere is characteristic of these groups. Salutogenic talk-therapy groups seem to be an important resource that stimulates health-promoting processes.

\section{Conclusion}

This chapter emphasizes the importance of high-quality social support in interplay with positive identity development. Social support and identity are crucial resistance resources when applying salutogenesis in mental healthcare settings. The issues of social support and identity are germane in any discussion of group therapy, but a salutogenic orientation gives explicit attention to their interplay as resistance resources. Of course, the research base is never complete, and the utility of salutogenic approaches needs to be further explored. Yet, examples presented in this chapter illustrate how a salutogenic orientation can be used to both formulate and to form interventions in mental healthcare settings. While intervention research is still quite limited, some experimental evidence is presented in the chapter that indicates both the feasibility and the effectiveness of taking a salutogenic orientation into the mental health setting.

\section{References}

Antonovsky, A. (1979). Health, stress and coping. Jossey-Bass.

Antonovsky, A. (1985). The life cycle, mental health and the sense of coherence. Israel Journal of Psychiatry and Related Sciences, 22(4), 273-280.

Antonovsky, A. (1987). Unravelling the mystery of health. Jossey-Bass.

Becker, C. M., \& Rhynders, P. (2013). It's time to make the profession of health about health. Scandinavian Journal of Public Health, 4l(1), 1-3.

Berger, H. (2003). Gesundheitsförderung-Ein neuer Weg in der Psychatrie. (Health promotion-A change of paradigm in psychiatry). Psychiatric Praxis, 30, 14-20.

Csikszentmihayi, M. (1997). Finding flow: The psychology of engagement with everyday life. Basic.

Cutrona, C. E., \& Russell, D. W. (1987). The provisions of social relationships and adaptation to stress. In W. H. Jones \& D. Perlman (Eds.), Advances in personal relationships (a research annual I) (pp. 37-67). JAI Press.

Deming, W. E. (2000). The new economics: For industry, government, education. MIT Press.

Duncan, B. L., Miller, S. D., Hubble, M. A., \& Wampold, B. E. (2010). The heart \& soul of change: Delivering what works in therapy (2nd ed.). American Psychological Association.
Eriksson, M., \& Lindstrøm, B. (2006). Antonovsky's sense of coherence scale and the relation with health: A systematic review. Journal of Epidemiology and Community Health, 60, 376-381.

Fugelli, P. (2012). Du blir formet av måten du danser med dine flokker på. Det er derfor egenskapene til flokkene våre er så viktige. [You are formed by how you dance with your flocks. That is why the properties of our flocks are so important]. Feature article. Dagbladet (a Norwegian national paper), 22.12.

Griffiths, C. A. (2009). Sense of coherence and mental health rehabilitation. Clinical Rehabilitation, 23, 72-78.

Højdahl, T., Magnus, J. H., Hagen, R., \& Langeland, E. (2013). "VINN"-An accredited motivational program promoting women's sense of coherence and coping. EuroVista, 2(3), 177-190.

Joachim, B., Lyon, D. D., \& Farrell, S. P. (2003). Augmenting treatment of obsessive compulsive disorder with Antonovsky's sense of coherence theory. Perspectives in Psychiatric Care, 39(4), $163-168$

Jormfeldt, H. (2011). Supporting positive dimensions of health, challenges in mental health care. International Journal of Qualitative Studies on Health and Well-Being, 6(2), 7126. https://doi. org/10.3402/qhv.vi2.7126

Landsverk, S. S., \& Kane, C. F. (1998). Antonovsky's sense of coherence: Theoretical basis of psychoeducation in schizophrenia. Issues in Mental Health Nursing, 19, 419-431.

Langeland, E., Gjengedal, E., \& Vinje, H. F. (2016). Building salutogenic capacity: A year of experience from a salutogenic talk-therapy group. International Journal of Mental Health Promotion, 18(5), 247-262. https://doi.org/10.1080/14623730.2016.1230070

Langeland, E. (2007). Sense of coherence and life satisfaction in people suffering from mental health problems. An intervention study in talk-therapy groups with focus on salutogenesis. Dissertation for the degree doctor rerum politicarum (dr.polit.), University of Bergen, Norway.

Langeland, E., Riise, T., Hanestad, B. R., Nortvedt, M. W., Kristoffersen, K., \& Wahl, A. K. (2006). The effect of salutogenic treatment principles on coping with mental health problems-A randomized controlled trial. Patient Education and Counseling, 62, 212-219.

Langeland, E., \& Vinje, H. F. (2013). The significance of salutogenesis and well-being in mental health promotion: From theory to practice. In C. Keyes (Ed.), Mental well-being: International contributions to the study of positive mental health (pp. 299-329). Springer.

Langeland, E., Wahl, A. K., Kristoffersen, K., \& Hanestad, B. R. (2007). Promoting coping: Salutogenesis among people with mental health problems. Issues in Mental Health Nursing, 28, 275-295.

Langeland, E., \& Wahl, A. K. (2009). The impact of social support on mental health service users' sense of coherence: A longitudinal panel survey. International Journal of Nursing Studies, 46(6), 830-837.

Lindstrøm, B. (2001). The meaning of resilience. International Journal of Adolescent Medicine and Health, 13(1), 7-12.

Lutz, J. (2009). Flow and sense of coherence: Two aspects of the same dynamic? Global Health Promotion, 16, 63-67.

Magrin, M. E., Bruno, C., Gheno, S., Scrignaro, M., \& Viganò, V. (2006). The power of stress: A salutogenic model of intervention. In A. Delle Fave (Ed.), Dimensions of well-being. Research and intervention (pp. 470-488). Milano.

Menzies, V. (2000). Depression in schizophrenia: Nursing as a generalized resistance resource. Issues in Mental Health Nursing, 21, $605-617$.

Sullivan, G. (1989). Evaluating Antonovsky's salutogenic model for its adaptability to nursing. Journal of Advanced Nursing, 14, 336-342. 
Weiss, R. (1974). The provisions of social relationships. In Z. Rubin (Ed.), Doing onto others: Joining, molding, conforming, helping (pp. 17-26). Prentice Hall.

WHO. (2005). Promoting mental health: Concepts, emerging evidence, practice: A report of the World Health Organization, Department of Mental Health and Substance Abuse in collaboration with the Victorian Health Promotion Foundation and the University of Melbourne. World Health Organization.
Yamazaki, Y., Togari, T., \& Sakano, J. (2011). Toward development of intervention methods for strengthening the sense of coherence (SOC): Suggestions from Japan. In T. Muto, T. Nakahara, \& N. E. Woo (Eds.), Asian perspectives and evidence on health promotion and education (pp. 118-132). Springer.

Open Access This chapter is licensed under the terms of the Creative Commons Attribution 4.0 International License (http://creativecommons. org/licenses/by/4.0/), which permits use, sharing, adaptation, distribution and reproduction in any medium or format, as long as you give appropriate credit to the original author(s) and the source, provide a link to the Creative Commons license and indicate if changes were made.

The images or other third party material in this chapter are included in the chapter's Creative Commons license, unless indicated otherwise in a credit line to the material. If material is not included in the chapter's Creative Commons license and your intended use is not permitted by statutory regulation or exceeds the permitted use, you will need to obtain permission directly from the copyright holder. 